\title{
Study on the optical quality and strength of glass edges after the grinding and polishing process
}

\author{
Paulina Bukieda $\mathbb{D}$ - Katharina Lohr • \\ Jens Meiberg • Bernhard Weller
}

Received: 5 February 2020 / Accepted: 5 May 2020 / Published online: 5 June 2020

(C) The Author(s) 2020

\begin{abstract}
Glass edges result from cutting glass sheets and a further optional finishing. The mechanical interference into the brittle material glass causes flaws and cracks at the edge surface. Those defects have an influence on the strength of the whole glazing. Within the scope of a research project at the Institute of Building Construction from the Technische Universität Dresden, the grinding and polishing process is examined in terms of characteristic visible effects on the glass edge and the edge strength. Thereby a special focus of the research project is the impact of various polishing cup wheels for the chamfer surface of annealed glass. The article presents some basics about the processing steps of glass edges surfaces, introduces the considered grinding and polishing cup wheels and gives an overview of the performed experimental examinations. A microscopic analysis enables a characterisation of typical defects at the surfaces. Furthermore, four-point bending tests are performed to determine the bending tensile stresses at failure. The combination of both methods enables an analysis of the fracture-causing defect before destruction and a correlation between the optical surface quality and the bending tensile stresses. Additionally, the microscopy could be used to support the adjustment of a grinding machine and control reproducible edge qual-
\end{abstract}

P. Bukieda $(\bowtie) \cdot$ K. Lohr $\cdot$ B. Weller

Technische Universität Dresden, Dresden, Germany

e-mail: paulina.bukieda@tu-dresden.de

J. Meiberg

Artifex Dr. Lohmann GmbH \& Co. KG, Kaltenkirchen, Germany ities. The evaluation shows that a special development of polishing cup wheels for the chamfer can improve the surface quality and consequently increases the edge strength.

Keywords Chamfer · Edge strength · Glass edge · Grinding $\cdot$ Microscopic analysis · Polishing

\section{Introduction}

1.1 Consideration of glass edge strength in the design

The mechanical and thermal loads in window and facade constructions are growing with modern architectural demands and firm requirements for building physics. With increasing glass formats and complex glass structures, the superposition of mechanical and especially thermal loads can cause critical stresses particularly in the edge areas. According to the current design codes in various European countries, the design value of annealed glass needs to be reduced for dimensioning glass edges (Feldmann and Kasper 2014, p. 55). In case of the German and Austrian standard (DIN 18008-1 2019 and ÖNORM B 3716-1 2016) a reduction of $80 \%$ of the characteristic bending strength of annealed glass is required. That reduction considers the high scattering of the edge strength due to the processing and represents a minimum level of the glass edge strength. The reduced resistance of the edge strength of annealed glass and the lack of adaptable load sce- 
narios on glass edges lead to insecurities. To ensure a certain level of safety in the design of glass structures and damage-free glazing, a further in-depth examination of the glass edges is necessary. Currently, planners often use tempered glass, which shows a higher edge strength. However, the higher edge strength comes with a risk of spontaneous breakage due to a nickel sulfide inclusion and a reduction of the optical quality as anisotropies can be visible. Furthermore, the use of tempered glass is very costly. A more efficient use of annealed glass is desirable. For that reason, a safety design approach and a production of annealed glass with an acceptable edge strength and a low scattering are necessary.

\subsection{Geometries and types of glass edges}

Glass edges result from the cutting of a glass sheet and further optional finishing. The cutting process defines the geometry and the size of glass panes. In the following grinding and polishing process, the material is eroded at the edge surface and the margins, to ensure the size accuracy and to improve the optical quality. The so-called processed edges reduce the risk of injury and enable further thermal tempering of the glass panes.

Figure 1 is showing the typical geometry of a cut edge in the back and a polished, further processed, edge with two diagonal chamfers in the front. Five areas, divided into surfaces and lines, are defined to explain the grinding process and to relate the location of the fracture origins to a defined area. The edge surface (e) describes the area perpendicular to the glass pane surface (p). The chamfer (c) defines the surface of the trimmed margins, which are usually at an angle of $45^{\circ}$ and run from both sides of the glass pane surface towards the edge surface. Furthermore, the transitions between the edge and the chamfer (tc) as well as between the chamfer and the glass pane surface (tp) are defined.

In the building industry, different types of glass edges are classified according to the standard DIN 1249-11 (2017). The cut edge is described with sharp margins, a clean cut area and irregular fracturing in the scratched area. In addition to the cut edge, there are four types of further processed edges with increasing processing steps and optical quality. To produce an arrised edge, the sharp margins and irregular fracturing of the cut edges are trimmed. The edge surface is not necessarily processed. Ground edge, smooth ground edge and polished edge are defined depending on the further grinding and polishing steps. During the grinding process, the rough, abrasive processing steps are always carried out first, which causes a rough appearance. Afterwards, the surfaces are polished with finer, quality-improving tools, which create a flat and transparent surface. However, the grinding and polishing process introduces new flaws and cracks at the edge surface, which have an influence on the bending tensile stresses at failure and may have to be considered for the edge strength of the whole glazing.

\section{State of the art}

\subsection{Experimental examinations on glass edges}

The working group Edge Strength of the Fachverband Konstruktiver Glasbau e.V. (FKG) performed a wide experimental study concerning the strength of the edge finishing types cut edge, arrised edge and smooth ground edge. Therein, over 1000 glass beams in 33 test series from six different manufactures were tested in four-point bending (Ensslen 2013). Additionally, a selection of specimens of each test series was examined microscopically at the edge surface before the destruction. Kleuderlein et al. (2014) presented the differences in the types of edge surfaces between manufactures in Fig. 2. For each type of glass edge, there are pictures of three different manufactures. Especially the quality of the arrised edge is differing strongly. A recording of the processing parameters revealed that the arrised edges were produced with different grinding machines (cross belt or grinding wheels).

The testing procedure for the strength determination of glass edges referred to the DIN 1288-3 (2000), which defines the four-point bending test of flat glass with a load introduction into the weak axis. However, for the special examination of the edge strength, the setup was modified to perform in-plane tests. This way, homogenous tensile stresses at the edges are generated, which increases the probability of a fracture directly from the edge and enables a determination of an edge strength (Ensslen 2013). The test series were evaluated statistically with a two-parameter Weibull distribution to determine $5 \%$ fractiles at $95 \%$ confidence level, which correspond to the characteristic bending strength of glass. Out of 33 test series, only two series 

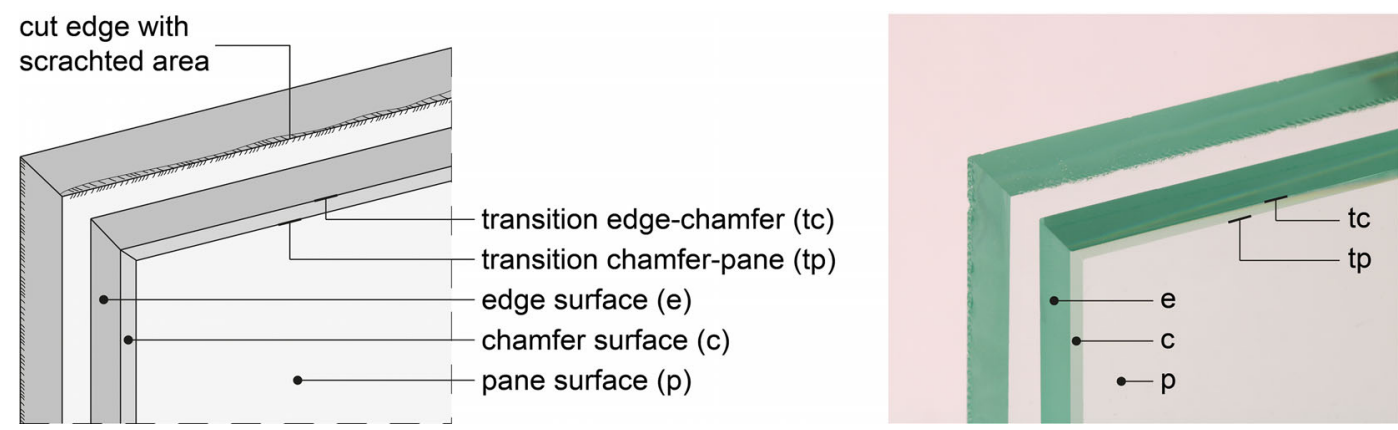

Fig. 1 Definition and terminology of typical areas of the glass edges within the presented examinations

showed $5 \%$ fractiles below the suggested characteristic edge strength for annealed glass of $36 \mathrm{~N} / \mathrm{mm}^{2}(80 \%$ of $f_{k}=45 \mathrm{~N} / \mathrm{mm}^{2}$ according to DIN 18008-1 (2019)). The maximum fractile was determined at a value of $64.84 \mathrm{~N} / \mathrm{mm}^{2}$. The widespread assumption that ground and polished edges always show a higher edge quality then cut edges could be disproved. A comparison within the same edge finishing shows that the manufacturer's impact is much higher than the finishing itself. Thus, a well cut edge can show a higher strength than a poorly ground edge with many defects. (Kleuderlein et al. 2014)

Besides the work of the working group Edge Strength, Lindqvist (2013) and Vandebroek (2014) examined the edge strength of annealed glass. Lindqvist (2013) performed microscopic analyses to predict the edge strength based on an identification of the critical crack. The results showed that it is difficult to detect the critical defects. Vandebroek (2014) examined the edge strength by bending tests to determine the influence of the load history, the stress corrosion, the size and the stress distribution. The examinations concentrated on the different edge types, different manufacturers and glass dimensions. The results confirm a large variation of the determined strength results between different manufactures and express the need of an examination of different edge finishing methods.

Lohr (2019) examined the grinding of thermally toughened glass. Within some microscopic examinations, it was noticeable that the transition areas between the surfaces tc and tp (see Fig. 1) showed a lot of defects and also a variety of fractures had their origins in the chamfer and transition areas. The transferability of the results of thermally toughened glass to annealed glass needs to be investigated.

\subsection{Generation of cutting process parameters}

After the wide study on the different types of glass edges, the working group Edge Strength focused on cut edges. With the results of the first study and a deeper examination of the cutting process, it was possible to generate a set of "good" cutting parameters for $8 \mathrm{~mm}$ thick glass, which lead to a reproducible edge strength of at least $45 \mathrm{~N} / \mathrm{mm}^{2}$ (Ensslen and MüllerBraun 2017). In addition, it was possible to determine optical characteristics, such as the depth of lateral and median cracks, which can be correlated to the edge strength. That way, an estimation of the cut edge strength can be based on optical methods (MüllerBraun et al. 2020).

\section{Objective}

The previous examinations of the working group Edge Strength of the $F K G$ (Ensslen 2013; Kleuderlein et al. 2014; Ensslen and Müller-Braun 2017) and Vandebroek (2014) showed, that the grinding and polishing process has a significant influence on the quality and strength of the glass edges. Despite the standardised types of design, there are considerable differences in the optical edge quality, as Fig. 2 is showing. There is a huge range of process parameters for all types of edges and a wide distribution between the manufacturers (Kleuderlein et al. 2014). Those facts underline the need for a deeper understanding of the further finishing processes, a detection and specification of process parameters and the production of comparable edge qualities. The manufacturing parameters of grinding and polishing are not yet examined scientifically. Only a reproducible edge quality, based on defined process 


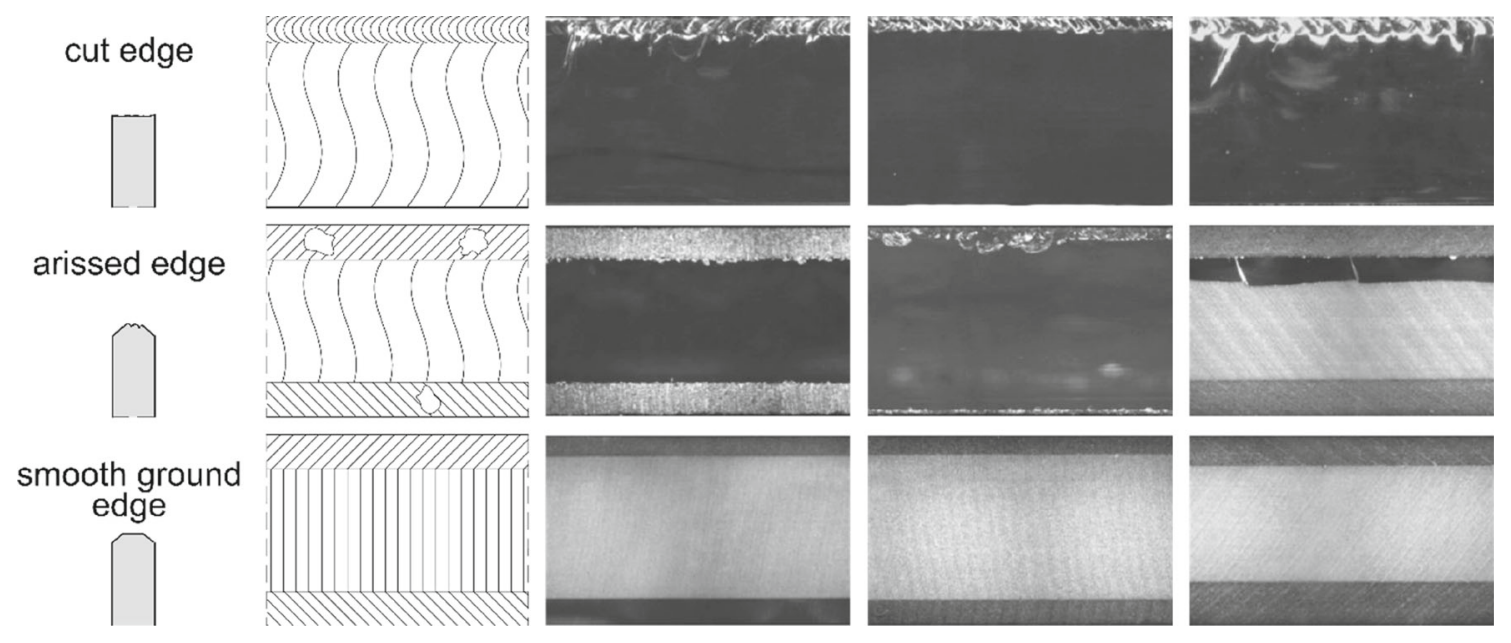

Fig. 2 Examples of edge finishing by different manufacturers for the quality cut edge, arrised edge and smooth ground edge according to DIN 1249-11 (2009) and Kleuderlein et al. (2014)

parameters, can minimize the scattering of the edge strength independent of different manufacturers. This is required to produce processed annealed glass edges with consistent quality and a consistent characteristic bending strength that does not require further reduction in the design process.

The objective of this study is to gain a deeper understanding of the impact of the finishing processes on the material and provide recommendations for the processing adjustments in order to achieve reproducible edge qualities with the support of optical methods. Therefore, the grinding and polishing process is examined and the adjustable parameters are identified. As a start, the edge finishing processes of one manufacturer are considered. The special focus of this examination is the reduction of flaws and cracks in the chamfer (c) and transition (tc) area to improve and create a reproducible optical quality along with a higher strength of glass edges. Hereby three different polishing tools and sizes of the chamfer are varied. To evaluate the impact of the parameters, an experimental testing procedure with a microscopic analysis method is developed. The microscopic analysis helps to understand the impact of finishing on the material by characterising the resulting surfaces and evaluating of the occurring defects. The testing procedure includes a microscopic record of the edge surfaces before the destructive tests and a localisation of fracture-causing defects after the destruction by the four-point bending test. Finally, the fracture-causing defects are correlated with the determined bending tensile stresses at failure.

\section{Edge finishing processes}

\subsection{The process of grinding and polishing}

In practice, different grinding machines are used to produce further processed glass edges. A cross belt machine, for example, consists of a moving belt, coated in abrasive material. To be processed, the glass has to be pressed manually against the belt. Some manufacturers produce arrised edges with cross belt machines. Another type is the CNC grinding machine, which grinds complex shapes under computer control. However, the most common way for producing further processed glass edges, and especially smooth ground and polished edges, are edge grinding machines. Those can be differed into vertical, single-sided and horizontal, double-sided edge grinding machines. The specimens of this study were processed with a single-sided, vertical edge-grinding machine of the type Rock 11 from the company Neptun, as shown in Fig. 3. Therefore, the further description of the grinding process is based on this method. The machine consists of eleven grinding and polishing stations. On each station, multi-grain tools, so called cup wheels, process the edge. From the outside, only the motors of the cup wheels are visible. The pictograph under the picture in Fig. 3 should 
Fig. 3 Single-sided grinding machine Rock 11 by Neptun with eleven grinding wheels
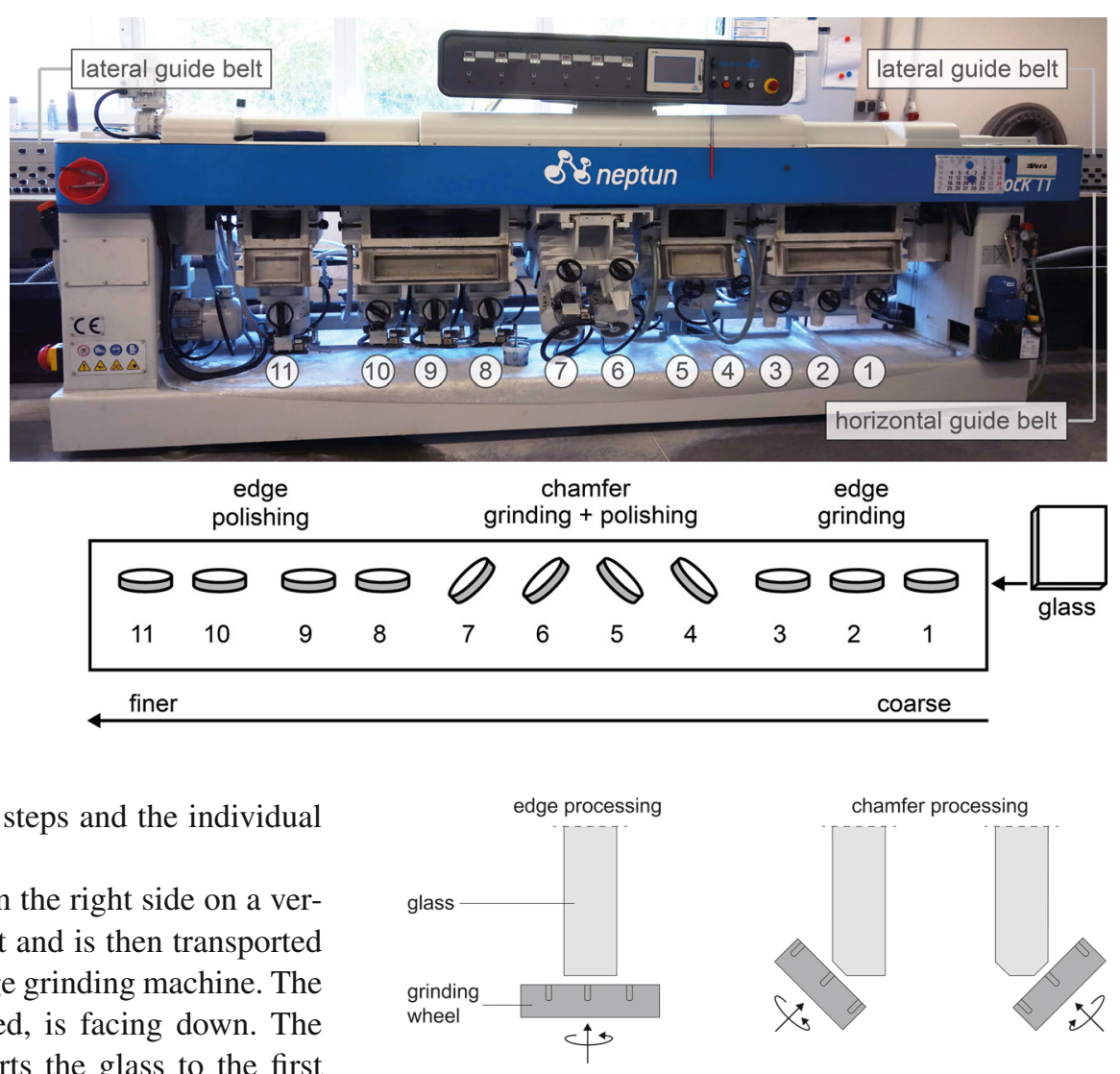

Fig. 4 Alignment of the grinding wheels during edge and chamfer processing

for a further polishing. The cup wheels towards the end of the process at the stations 8 to 11 are finer. They reduce the surface roughness and produce high transparency. Depending on the type of edge, the required stations can be separately switched on in the process. The polished edge passes through all stations and thus belongs to the highest quality level. Matching configurations of the grinding wheels and other process parameters are essential for the production of high-quality glass edges.

\subsection{Grinding and polishing cup wheels}

During the grinding process, microscopically small and geometrically undefined breaking parts are removed from the glass edge by the use of grinding and polishing cup wheels. These differ in the composition of the bonding system and the grain size. Figure 5 


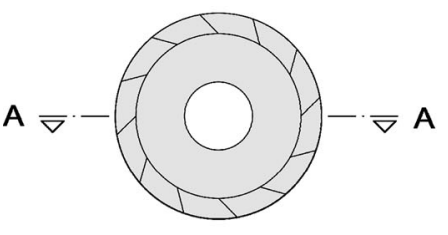

section A-A

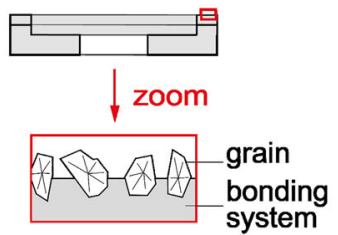

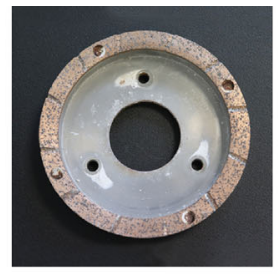
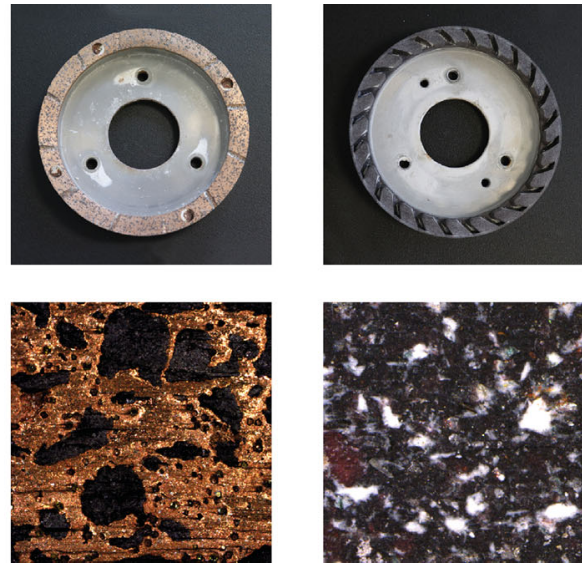
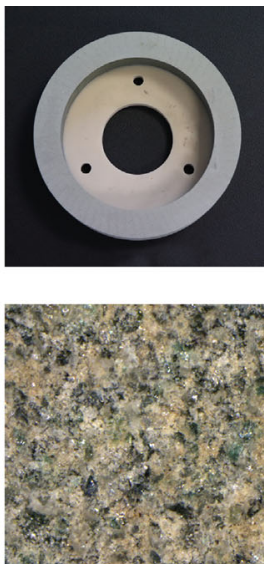

Fig. 5 Different grinding and polishing cup wheels and their microscopic surfaces

Fig. 6 Different conditions of the surface of cup wheels

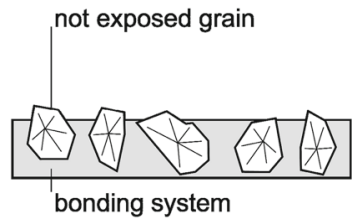

shows examples of different grinding and polishing cup wheels and their microscopic surfaces.

Rough grains in combination with hard, metallic or resin bonds are used for abrasive processing steps. The left picture of Fig. 5 shows a metallic bonded diamond grinding wheel, which ensures high material removal by the use of extremely hard diamond grains. They create a rough appearance on the processed surfaces. The removed material can accumulate in the segments and then be washed out by the cooling water. The middle picture shows a synthetic resin-bonded diamond grinding wheel, which is similar to the metallic bonded one but softer due to the use of a synthetic resin-based bonding system. This results in a smooth material removal. The right part of Fig. 5 shows a polishing cup wheel with a fine grain of corundum. Polishing cup wheels are created by combining abrasive grains such as silicon carbide, corundum or cerium oxide with elastically bonded backing materials such as polyurethane, rubber or modified synthetic resins in various degrees of elasticity. The chemical structure of the respective bonding system in combination with the abrasive grain influences the final properties of the tool. Finer grains in softer, elastic binders are used to create smooth and transparent surfaces. Cerium oxide is a suitable grain for high polishing, as it enables a removal by mechan-
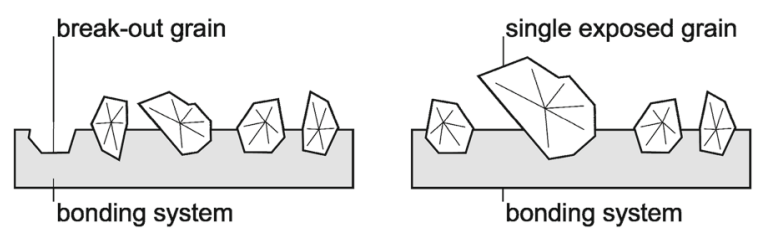

ical and chemical grinding. The chemical reaction dissolves atoms from the glass, which then stand out from the surface. In this way, a smoothing of tiny irregularities of the edge is achieved.

A cup wheel must always have multiple, exposed abrasive grains at its surface to process glass edges. This way it can work efficiently. To produce the intended abrasive effect, the abrasive grains should not be abraded faster than the bonding system, break-out of the bonding system nor should one single grain be exposed (Fig. 6).

\subsection{Grinding parameters on the surface quality}

The final edge quality is a result of the combination and amount of cup wheels, several process parameters and their suitable interaction. Currently there are no commonly known optimised process parameters for the grinding and polishing process that refer to a defined quality or strength of edges. In practice the optimisation is based on the visual quality of the glass edge. The influences of the manufacturer and grinding machine are high and are not sufficiently examined. However, the influences of the individual process parameters can be derived from the grinding working principles. A high number of rotations of the cup wheels combined 

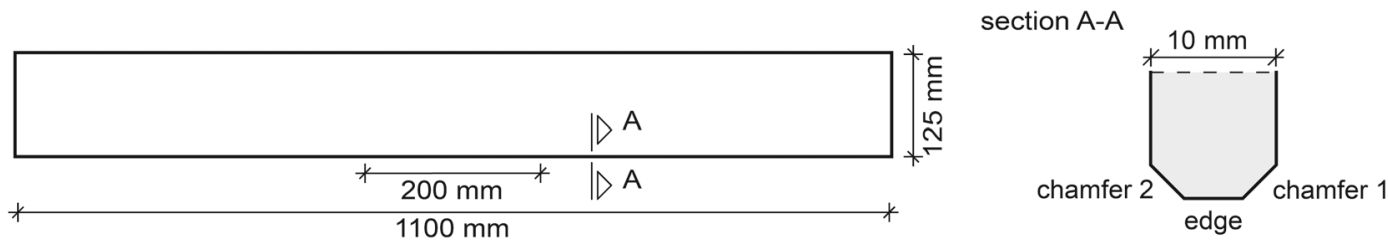

Fig. 7 Geometry of the examined specimen

with slow velocity ensures that the grinding wheel is in contact with the glass surface more often. This should improve the physical material removal and polishing processes. Furthermore, the amount and cleanliness of the cooling water can have a significant influence on the quality.

In the present observations, the chamfer surface and the transition areas are of special interest. Therefore, three different polishing cup wheels for the chamfer are examined optically and in terms of the edge strength.

\section{Examination program}

\subsection{Overview}

In order to evaluate the quality of the edge and chamfer surfaces and to obtain conclusions about the defects, which can cause the fracture, a three-step experimental test program was developed. First, the edges and chamfer surfaces were recorded microscopically and examined. Subsequently, four-point bending tests were carried out. In the last step, the origin of the fracture was localised and the fracture-causing defect was detected by a comparison with the recorded images of the surface before breakage.

\subsection{Specimen}

The specimens produced are beams measuring $125 \mathrm{~mm} \times 1100 \times 10 \mathrm{~mm}$ with a polished edge (Fig. 7). The dimensions are based on the design of the setup for the four-point bending test. The polished glass edge was chosen, as the production of edges with a high optical quality was one of the aims of the research project. To examine a rather big surface and that way gain more information about the grinding and polishing processes, the thickness of $10 \mathrm{~mm}$ was chosen for the specimens. The definition of chamfers as chamfer
1 and chamfer 2, according to Fig. 7, is necessary for a clear comparability. The classification is determined according to the grinding pattern. The specimen were produced with an oversize and then cut, as the grinding machine needs a minimum height of $250 \mathrm{~mm}$ to process the edges.

\subsection{Microscopic analysis}

The microscopic surface analysis was performed with a digital light microscope from Zeiss with a possible magnification of $34 \times$ to $1100 \times$. The edge and chamfer surfaces of all test specimens were marked and recorded. That enabled a characterisation of the edge quality and a further localisation of the fracture-causing defect. The recorded surfaces cover the middle of the specimen and have a length of about $200 \mathrm{~mm}$ (the area is marked in Fig. 7). That special area corresponds to the loaded area in the following four-point bending test. Hence, there is a high probability that the origin of the fracture will occur in that area. The edge surface is recorded with a $70 \times$ magnification, the chamfer surfaces at a magnification of $100 \times$. Figure 8 a shows the microscope with an inclined support for recording the images of the chamfer surfaces and an example of a microscopic recording of approximately $20 \mathrm{~mm}$ of a chamfer surface (Fig. 8b).

\subsection{Four-point bending}

The four-point bending tests were performed referring to the DIN EN 1288-3 (2000) and the examinations of the working group Edge Strength of the $F K G$ by loading the glass specimens in bending about the strong axis. The examined edge is facing downwards where the bending tensile stresses occur. Figure 9 is showing the test set up at the Technische Universität Dresden and a corresponding pictograph. The ball bearing and 
(a)
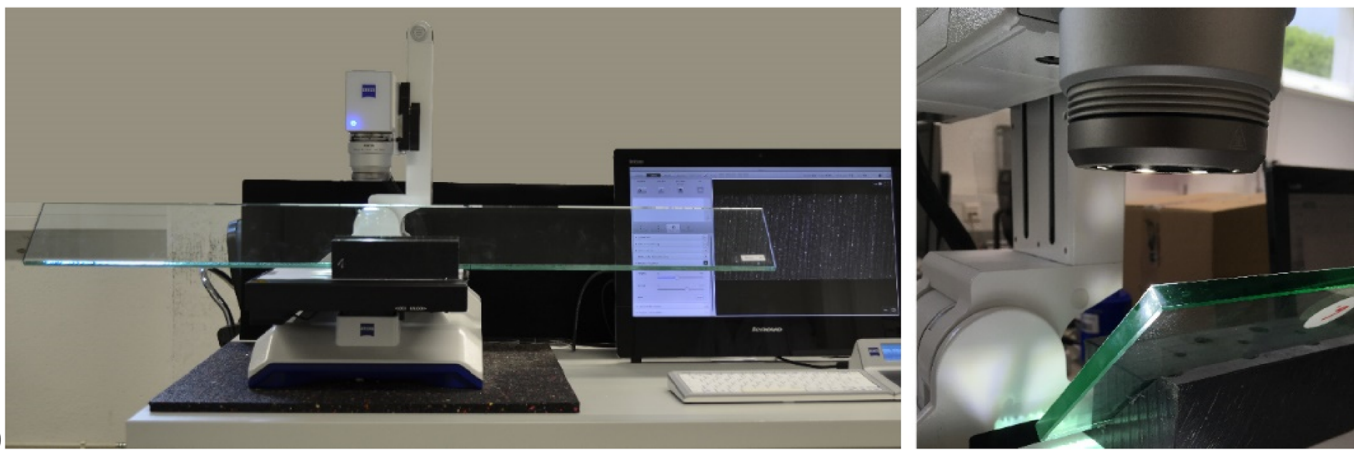

mark

(b)

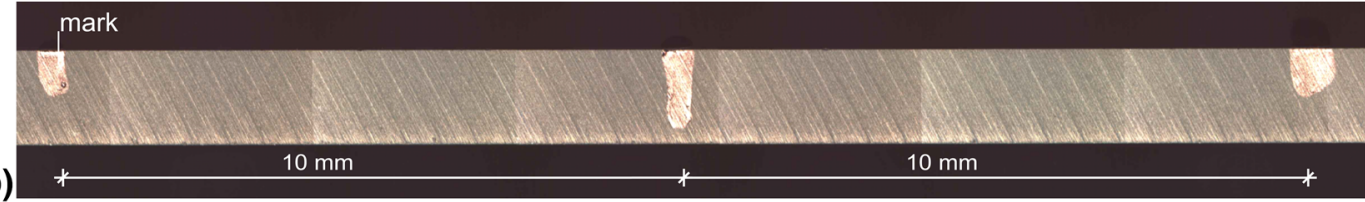

Fig. 8 a Microscopy of the chamfer surfaces with a digital microscope from Zeiss; b Example of a recorded chamfer surface with marks

the lateral supports at beam ends are combined in a supporting ball-bearing system. The specimen is vertically supported on $80 \mathrm{~mm}$ wide POM blocks, with a span of $1000 \mathrm{~mm}$. The load is introduced punctually within a span of $200 \mathrm{~mm}$ via small POM-blocks, which rest on the upper glass edge. The fracture tests are conducted with a constant loading rate of $2 \mathrm{~N} /\left(\mathrm{mm}^{2} \mathrm{~s}\right)$ until breakage. After the destruction, the fracture load is measured.

\subsection{Defect analysis}

After the fracture test, the global position of the fracture $\mathrm{x}_{\text {glob }}$ is determined to decide whether a test will be evaluated or not (Fig. 10). Only fracture origins within the loaded area are evaluated. The closer look at the fracture mirror allows to determine the starting of the fracture origin of the initial crack (Quinn 2016, 7-10). A further differentiation is made between a starting from the edge surface (e), the chamfer surface (c), the transition area (tc) or the glass pane surface (p) to localise the fracture-causing defect on the recorded images of the intact surfaces. The circle-center of the fracture mirror in Fig. 10 points to the initial crack at the chamfer surface on side 2 .

\subsection{Processing Parameters}

All specimens were ground with a velocity of $2 \mathrm{~m} / \mathrm{min}$ and a grinding depth of $1 \mathrm{~mm}$. The grinding depth describes the amount of the material removal of the glass edge during the grinding process. Before the grinding process, the visible median cracks which result from the cutting process (Müller-Braun et al. 2020), were measured with a length of about $300 \mu \mathrm{m}$. With the chosen grinding depth of $1 \mathrm{~mm}$ the visible median cracks from the cutting process are completely removed. Therefore, it is assumed, that an influence of the cutting process is excluded. The assumption though should be verified in a further test series by grinding different qualities of cut edges with constant grinding process parameters. The bonding system and grain type of the used cup wheels are listed in Table 1. The adjustable contact pressure of each grinding cup wheel was set and recorded according to the manufacturer's experience and the macroscopic optical results during the production. As it is dependent on the abrasion of the used cup wheel, it can vary within the test series.

Table 2 gives an overview of the tested series. In total, three different polishing cup wheels for the chamfer of the company Artifex were examined for the stations 5 and 7 (according to Fig. 3). For the specimens of test series A, a resin-bonded polishing cup wheel with a very fine grain of corundum was used. This kind of pol- 


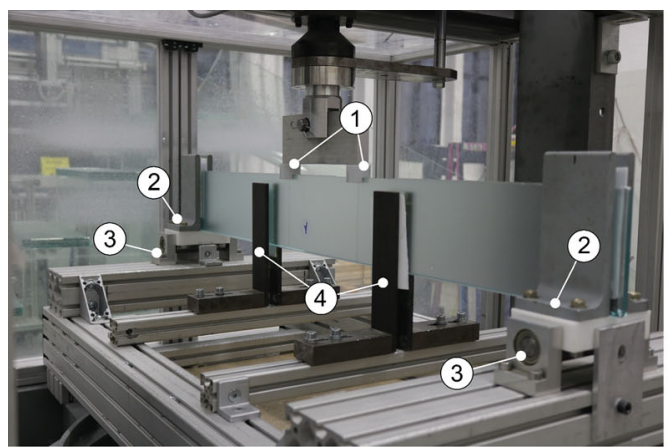

(1) load introduction with POM-blocks

(2) supporting

(3) ball bearing

(4) L-profiles

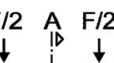

[mm]

A-A

$\stackrel{2}{\sim}$
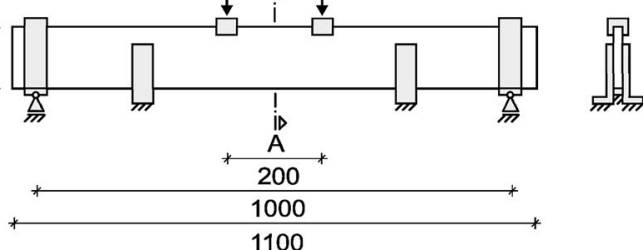

Fig. 9 Test set up of the four-point bending tests

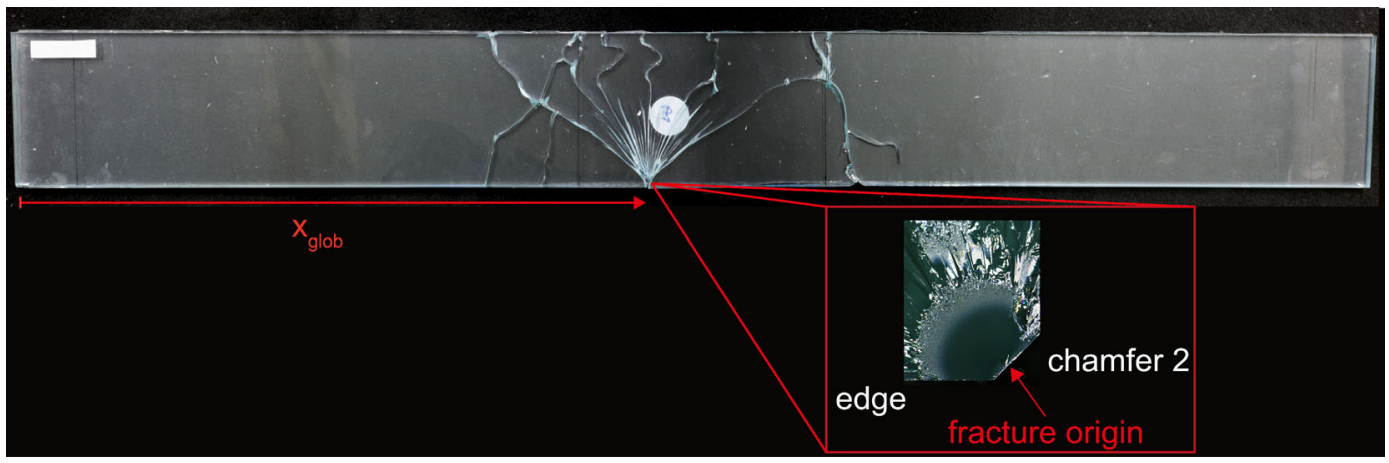

Fig. 10 Localisation of the fracture point with the measurement of $x_{\text {glob }}$ and the fracture mirror with fracture origin

Table 1 Grinding wheels used in the edge grinding machine

\begin{tabular}{|c|c|c|c|c|c|}
\hline Station & Function & Bonding system & Grain type & Grain dimension* & Contact pressure [bar] \\
\hline 1 & Edge grinding & Resin & Diamond & D151 & Rigid \\
\hline 2 & Edge grinding & Resin & Diamond & D76 & Rigid \\
\hline 3 & Edge grinding & Resin & Diamond & D54 & Rigid \\
\hline 4 and 6 & Chamfer grinding & Resin & Diamond & D64 & Rigid \\
\hline 5 and 7 & Chamfer polishing & See Table 2 & & & \\
\hline 8 & Edge polishing & Polyurethane & Corundum & F60 & $2.1-2.25$ \\
\hline 9 & Edge polishing & Polyurethane & Corundum & F60 & $2.1-2.3$ \\
\hline 10 & Edge polishing & Polyurethane & Cerium oxid & - & $3.4-3.5$ \\
\hline 11 & Edge polishing & Resin & Cerium oxid & - & $2.9-3.1$ \\
\hline
\end{tabular}

*Dimension of grain types are defined by their types. The grain dimension of diamonds (D) is described in DIN ISO 6106 (2015), the grain dimension of corundum (F) is described in DIN ISO 8486 (1997)

ishing cup wheel is classified as hard. The specimens of test series B were produced with a polishing cup wheel made of polyurethane as bonding and a medium grain size corundum. Therefore, a softer polyurethane foam is produced, what classifies the polishing cup wheel as soft. Within the scope of the research project, special polishing cup wheels made of a polyurethane bonding system and an internal grain were developed for the chamfer. Those are expanded into a finely porous but hard polyurethane foam. The exact composition is subject to the non-disclosure agreement with the company 


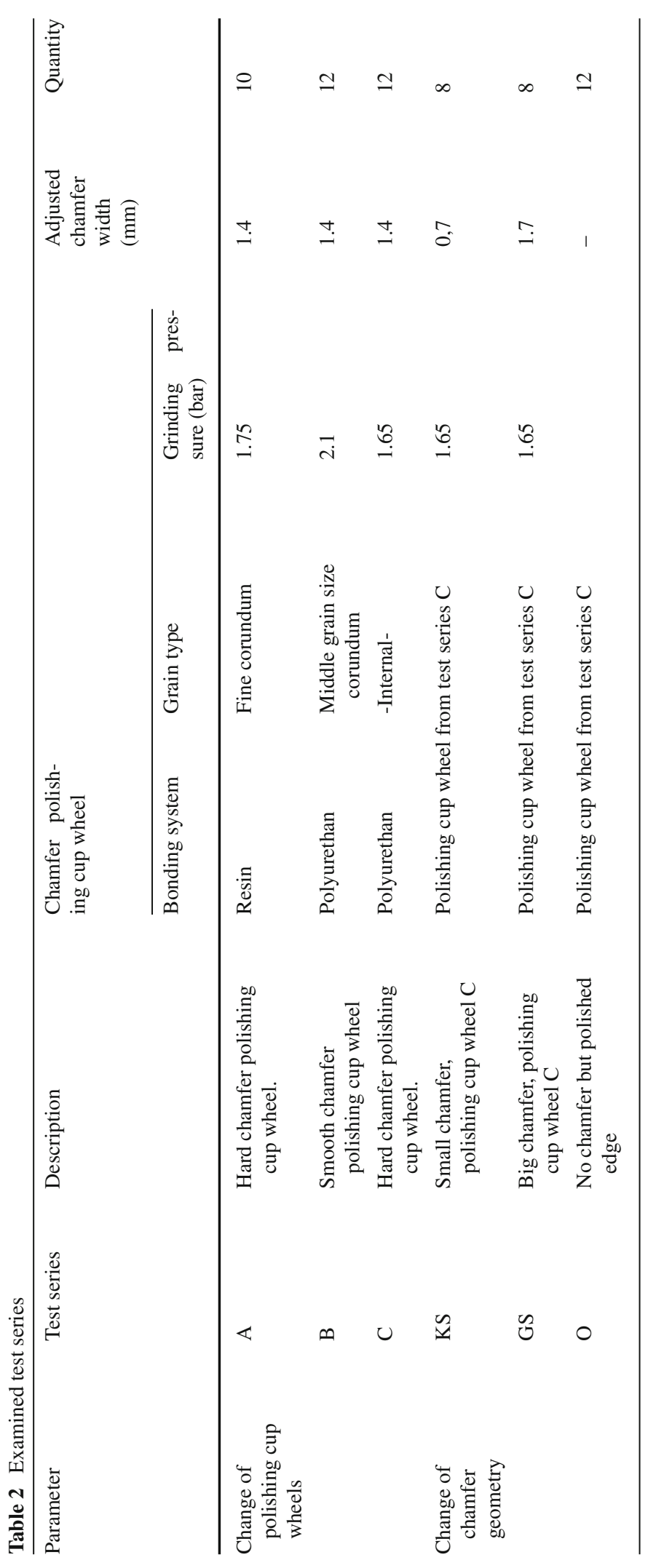


Artifex. The specimens of test series $\mathrm{C}$ were produced with the especially developed polishing cup wheel.

In addition, three test series with a varying chamfer size were examined to test the influence of a varying amount of material removal of the chamfer. Therefore, the grinding cup wheels for the chamfer were adjusted manually. The general adjustment removes about $1 \mathrm{~mm}$ of the edge surface on each side with an angle of $45^{\circ}$, which results in a width of the chamfer surface of $1.4 \mathrm{~mm}$. For a small chamfer (test series KS), the adjustments should remove approximately $0.5 \mathrm{~mm}$ of the edge width on each side, what leads to a chamfer width of $0.7 \mathrm{~mm}$. The big chamfer (test series GS) with a width of approximately $1.7 \mathrm{~mm}$ was created by adjusting the chamfer grinding cup wheels to a $1.5 \mathrm{~mm}$ removal on each side. In addition, a test series with a polished edge but no chamfer was produced (test series $\mathrm{O})$. The aim was to avoid defects caused by the production of the chamfer. For the test series $\mathrm{O}$ the stations 4 to 7 were shut down. Per test series, eight to twelve test specimens were produced.

\section{Results}

\subsection{Typical surfaces and defects}

The microscopic analysis helped to gain general information about the processed edge and chamfer surfaces. Some typical surfaces and occurring defects are shown in Fig. 11. The impact of the cup wheels on the glass leaves a grinding pattern at the surface, which can be associated with the direction of rotation of the cup wheels. The grinding pattern can be recognised as a consistent pattern of grooves at the surface. Furthermore, typical defects as individual scratches in the direction of the grinding pattern, flaws in the transition areas, further described as chippings and conchoidals, were determined.

Individual visible scratches (Fig. 11, left) in the direction of the grinding pattern can be caused by an insufficiently dimensioned removal of the glass abrasion, an exposed or broken-out abrasive grain from the cup wheel. Chipping and conchoidals are created due to the material removal of both the edge and the chamfer area. They occur naturally at the point where the material is broken out (Fig. 11, middle and right). As the defects are produced during the grinding or polishing process, they are classified as typical. The follow- ing analysis contains the comparison of these typical defects within the varying test series.

\subsection{Microscopic analysis of the test series}

The microscopic images of the surfaces allow for the first evaluation and characterisation of the edge quality. Figure 12 shows representative sections of the surfaces of chamfer 1, the edge and chamfer 2 of the test series with different polishing cup wheels (test series A, B and C). The arrangement of the images corresponds to the transition areas of the adjacent surfaces. The chamfer surfaces are shown $4 x$ enlarged, compared to the edge surfaces.

The comparison of the edge surfaces of the individual test series shows no significant differences. On closer inspection, the grinding pattern with slight parallel grooves can be seen. However, the microscopically visible grinding pattern is hardly visible on a macroscopic level. Therefore, the edge surface is clearly classified as polished.

The observation of the chamfer surfaces of the test series reveals different qualities, which can be traced back to the properties of the varying chamfer polishing cup wheels.

\section{Series A}

- Chamfer surfaces grooves can be seen in the grinding direction

- Chamfer surfaces show a clear, sharped-edged transition area with slightly visible chippings and conchoidals

- The size of the flaws in the transition area on the chamfer surfaces is in the range of $50-150 \mu \mathrm{m}$

Series B

- Chamfer surfaces show dark areas at the transition area towards the edge surface

- The visible darkening towards the edge is caused by a rounding of the chamfer, the deeper level is exposed less in the microscopic image and is therefore darker

- With a radius of about $250 \mu \mathrm{m}$, the rounding is not visible macroscopically

- The size of the flaws in the transition area on the chamfer surfaces is in the range of $50-150 \mu \mathrm{m}$

Series C

- The chamfer surfaces show less visible grooves, the grinding direction is hardly visible 

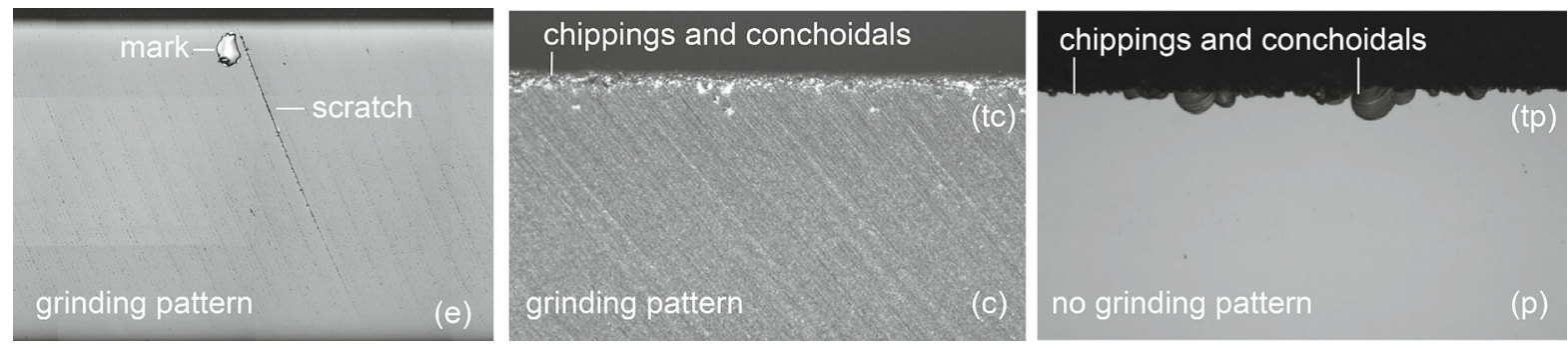

Fig. 11 Microscopic images of typical defects and grinding pattern. Left: polished edge surface with a slight visible grinding pattern and a scratch; middle: chamfer surface with grinding pattern and flaws in the transition area; right: pane surface with flaws

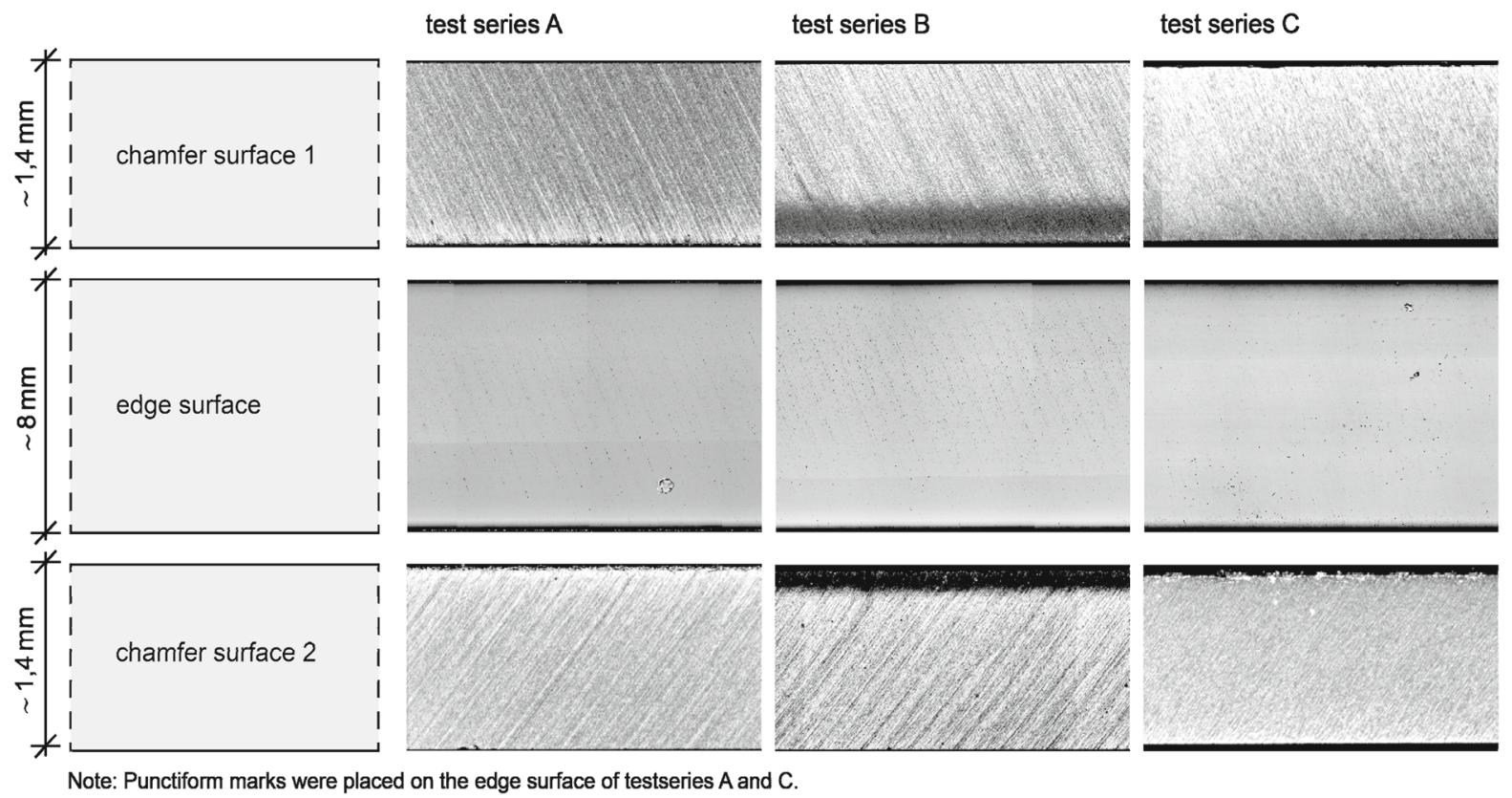

Fig. 12 Microscopic images of the typical surfaces of test series A, B and C

- The transition between the edge and chamfer surface 1 is clear and sharp-edged

- At the transition to chamfer surface 2 , the area with chippings and conchoidals is about $80 \mu \mathrm{m}$

Thus, the polishing cup wheel $\mathrm{C}$ shows the best optical results with the least amount of chippings and conchoidals. Macroscopically, the specimen of test series $\mathrm{C}$ also showed the best optical chamfer quality with the least defects.

Figure 13 shows microscopic images of the test series with a varying chamfer size (test series GS, KS and $\mathrm{O}$ ). The chamfer polishing cup wheel $\mathrm{C}$ was used for the production of the chamfer, as it showed the best results in the polishing cup wheel study. Chipping and conchoidals of the test series KS and GS occur in a range of $80 \mu \mathrm{m}$. Only one specimen of test series GS showed exceptional chipping and conchoidals in a range of $450 \mu \mathrm{m}$. Besides this single specimen the chamfer surface quality was reproducible. The differing size was not recognisable. It was assumed that the amount of the material removal could be noted in the transition areas through occurring chipping and conchoidals.

One of each chamfer surfaces of the test series KS and GS shows the same smooth grinding pattern with almost no visible direction as test series $\mathrm{C}$ in Fig. 12. In test series KS a grinding pattern is visible in chamfer 2, while test series GS shows a grinding pattern in the surface of chamfer 1 . Due to the grinding pattern of the edge and chamfer surfaces it is possible to con- 


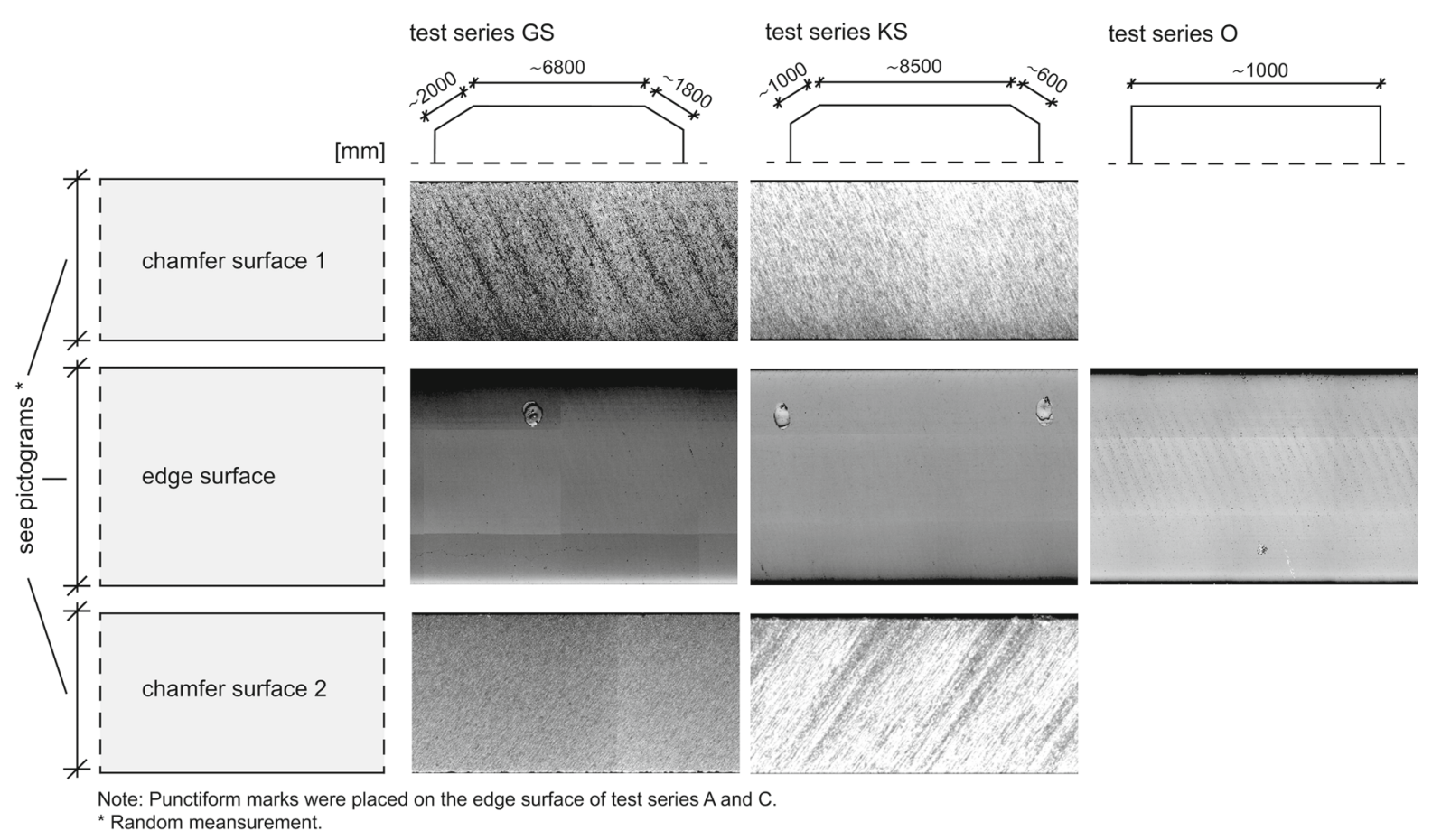

Fig. 13 Microscopic images of the typical surfaces of test series GS, KS and OI

firm that the specification of the chamfers is correct. As the manual adjustment of the chamfer grinding cup wheel at station 4 and 6 (according to Fig. 3) is the only difference between the test series KS and GS, the interaction between the grinding pressure and the amount of material removal can cause the visible conspicuity. In addition, a random measuring of the chamfer width of the specimens showed that the manual adjustment results in different chamfer sizes.

For the test series $\mathrm{O}$ no chamfer was produced. Therefore, only the edge surface is presented in Fig. 13. The edge surfaces corresponds to the optical quality of the other test series. In the transition area of the edge surface of test series $\mathrm{O}$ to the pane surface 2, single chippings and conchoidals with a range of about $300 \mu \mathrm{m}$ were detected. As no chamfer is produced, they can be traced back to the material removal of the glass edge

\subsection{Bending tensile stress analysis}

For the study of varying chamfer polishing cup wheels and chamfer sizes, in total 62 specimen were tested. The bending tensile stresses of each specimen were determined from the measured fracture load according to the Euler-Bernoulli beam theory. As part of the analysis, the global position $\mathrm{x}_{\mathrm{glob}}$ of the fracture, as well as, the exact fracture origins were considered. Fractures with origins in the edge surface (e), the chamfer surface (c), the transition area between the edge and chamfer surface (tc) and the pane surface ( $p$ ) were found. Ten specimens showed a fracture origin from the pane surface and were not considered in the evaluation. Besides, nine specimens broke outside the loaded area, where the highest tension is assumed. Those specimens as well were not taken into account in the evaluation. As only the loaded area was recorded microscopically, those defects cannot be characterised and further correlated with the microscopic images.

Figure 14 is showing the determined bending tensile stresses for each test series in form of boxplots. The thick line in a box marks the median of the evaluated values, while the numbers (n) over the boxes give the number of the evaluated specimens. The grey boxplots contain all the specimens of a test series with a fracture from the loaded area. A further breakdown is made depending on the fracture origin with an initial crack from the edge (purple boxplots), from the transition (blue boxplots) and the chamfer (green boxplots). 


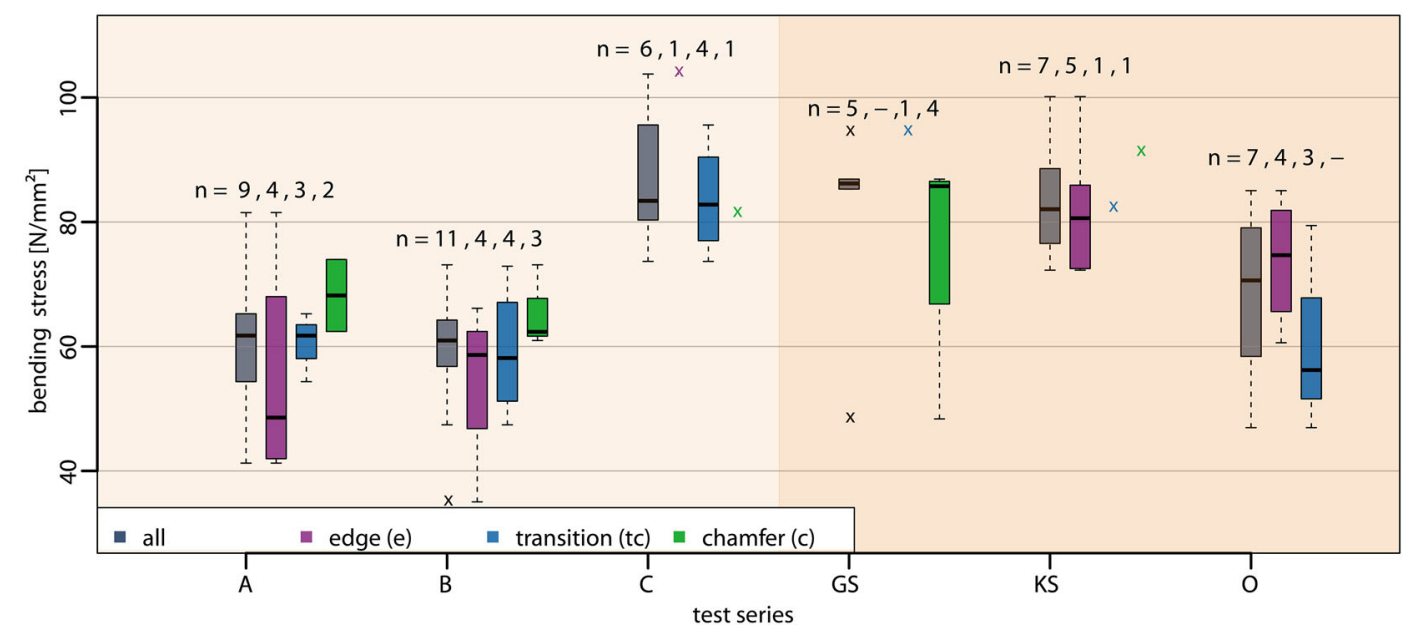

Fig. 14 Boxplots of the bending tensile stresses of the examined test series with a differentiation of the fracture origin

Generally, the bending tensile stresses of each test series show a big scattering. Comparing the test series $\mathrm{A}, \mathrm{B}$ and $\mathrm{C}$ with different polishing cup wheels, test series $\mathrm{C}$ showed clearly the highest determined bending tensile stress. Additionally, Table 3 shows the respective minimal, maximal and mean values. Test series $\mathrm{C}$ reached with $103.77 \mathrm{~N} / \mathrm{mm}^{2}$ the highest bending tensile stress and with $86.69 \mathrm{~N} / \mathrm{mm}^{2}$ the highest mean value. Looking at the bending tensile stresses of test series GS and KS, based on the boxplots and Table 3 they are comparable to the test series C. Only one specimen of test series GS is showing a relatively low bending tensile stress. Test series $\mathrm{O}$ with no chamfer is showing a big scattering but compared to the test series $\mathrm{A}$ and B still slightly higher bending tensile stresses.

So far, the differentiation between the positions of the fracture origin could not show clear trends concerning the bending tensile stresses. Counting the number of specimens with an initial crack from the chamfer or the transition area, $60 \%$ of the specimens had a breakage form the chamfer and $40 \%$ of the edge. That confirms the fact that the chamfer and transition areas are of special interest as they show more fracture causing defects than the edge. As the number of evaluated specimens in each test series is rather low, the statements have to be treated with caution. However, the trend of the results will be discussed and taken as foundation for further examinations.

\subsection{Determination of fracture-causing defects}

The determination of the fracture-causing defects enables a correlation with the bending tensile stresses. To determine the fracture-causing defect, the distance between the fracture origin and the marks was measured on the fragment. With this distance the corresponding spot on the intact images was determined. Figure 15 shows the fracture-causing defects of the specimen with the minimal and maximal determined bending tensile stresses of each test series. The presented pictures are scaled with different magnifications to enlarge the visibility of the defect. A twodimensional geometrical measurement of the defect could still not provide sufficient information for a correlation and is therefore not presented here.

The first row in Fig. 15 shows the correlation of the lowest bending tensile stresses of each test series. The microscopic images show clear defects. The specimen with the lowest bending tensile stress of test series GS can be characterised as chippings and conchoidals. Those kinds of defects were found repeatedly at the whole specimen. Hence, the microscopic analysis and comparison with the other specimen in the test series GS showed that it was the only specimen of the series with that size of chippings and conchoidals. Comparing that observation with the determined bending tensile stresses, the scattering of the test series GS is explained. The fracture-causing defect of the specimen with the lowest bending tensile stress of test series A is a scratch. The scratch is perpendicular to the edge margin. This 
Table 3 Results of the four-point bending tests

\begin{tabular}{llllllll}
\hline & A & B & C & GS & KS & O & All \\
\hline Quantity & 9 & 11 & 6 & 5 & 7 & 7 & 45 \\
Minimum $\left(\mathrm{N} / \mathrm{mm}^{2}\right)$ & 41.26 & 35.03 & 73.67 & 48.36 & 72.26 & 46.96 & 35.03 \\
Maximum $\left(\mathrm{N} / \mathrm{mm}^{2}\right)$ & 81.52 & 73.12 & 103.77 & 94.45 & 100.14 & 85.04 & 103.77 \\
Median $\left(\mathrm{N} / \mathrm{mm}^{2}\right)$ & 61.75 & 60.69 & 83.40 & 86.19 & 82.05 & 70.61 & 72.51 \\
Mean $\left(\mathrm{N} / \mathrm{mm}^{2}\right)$ & 59.74 & 59.22 & 86.69 & 80.24 & 83.53 & 68.22 & 70.51 \\
$( \pm \mathrm{SD})$ & $( \pm 13.27)$ & $( \pm 10.90)$ & $( \pm 11.04)$ & $( \pm 18.19)$ & $( \pm 10.00)$ & $( \pm 14.01)$ & $( \pm 16.53)$ \\
\hline
\end{tabular}

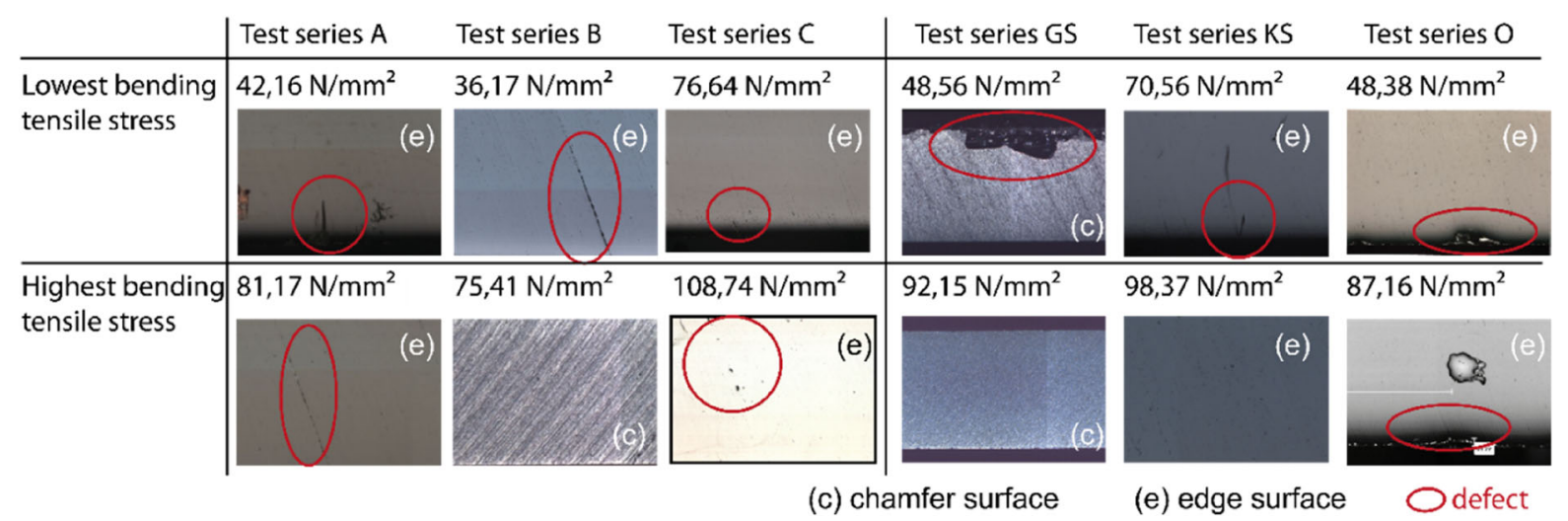

Fig. 15 Fracture-causing defects of the lowest and highest bending tensile stresses at the examined test series

kind of defect is not representative for the grinding and polishing process, as it is not in the direction to the grinding-pattern. It is assumed that it was caused after the grinding and polishing process.

The second row in Fig. 15 shows fracture-causing defects with the highest bending tensile stresses of the test series. B, GS and KS were not showing any optical irregularity, what supports the thesis that a high optical quality of the surfaces correlates with higher bending tensile stresses. However, not every clear defect is causing an early breakage. The fracture-causing defects of the strongest specimen of test series A and the weakest specimen of test series B are both scratches in the direction of the grinding pattern. Though the optical appearance on the surface is quite similar, the bending tensile stresses, differ by about $45 \mathrm{~N} / \mathrm{mm}^{2}$. Digital microscopy is a non-destructive and contactless method for surface analysis, with a record of two-dimensional surface images. Therefore, the depth of scratches is not measurable. Due to the focus and lightning some scratches and damages can be detected and characterised as stronger by comparison the surrounding area. Especially narrow medial cracks, which cause an early breakage, cannot be detected.

\subsection{Strength determination}

The parameter combination of the series $\mathrm{C}$ and $\mathrm{KS}$ showed the best results. To determine strength values with a statistical significance, second test series with 30 specimens each were produced. A lot of fracture origins occurred outside the loaded area, what reduced the amount of specimen for the evaluation. Table 4 shows the results of the statistical evaluation with a two-parameter Weibull distribution. The determination of $5 \%$ fractiles with a confidence level of $95 \%$ resulted in a value of $42.74 \mathrm{~N} / \mathrm{mm}^{2}$ for test series C_2 and a value of $52.09 \mathrm{~N} / \mathrm{mm}^{2}$ for test series KS_2. Though test series C_2 shows a lower $5 \%$ fractile, both are clearly above the limit value of $36 \mathrm{~N} / \mathrm{mm}^{2}$ according to DIN 18001 (2019).

Ten specimens from each of the second test series, C_2 and KS_2, were examined microscopically. The microscopic analysis revealed surfaces are comparable 
Table 4 Results of second test series C_2 and KS_2 with an enlargement of specimen

\begin{tabular}{lll}
\hline & C_2 & KS_2 \\
\hline Quantity & 21 & 17 \\
Minimum $\left(\mathrm{N} / \mathrm{mm}^{2}\right)$ & 35.87 & 58.48 \\
Maximum $\left(\mathrm{N} / \mathrm{mm}^{2}\right)$ & 92.83 & 94.48 \\
Median $\left(\mathrm{N} / \mathrm{mm}^{2}\right)$ & 76.40 & 73.34 \\
Mean $\left(\mathrm{N} / \mathrm{mm}^{2}\right)$ & 73.42 & 74.64 \\
$( \pm \mathrm{SD})$ & $( \pm 14.32)$ & $( \pm 9.87)$ \\
Weibull parameters & $\lambda=5.10$ & $\lambda=8.52$ \\
& $\beta=79.95$ & $\beta=78.90$ \\
5\% fractile $\left(\mathrm{N} / \mathrm{mm}^{2}\right)$ & 42.74 & 52.09 \\
\hline
\end{tabular}

to the first test series. As some of the analysed specimens broke outside the loaded area, a correlation and detection of fracture-causing defects was possible for only nine specimens in total for both test series. The determination of the fracture-causing defects revealed some untypical defects.

\section{Discussion}

7.1 Typical defects in dependence of the finishing process

The quality, size and frequency of the defects can give an idea of a good interaction of the single processing stations and processing parameters or reveal a maladjustment. The combination of high contact pressures, excessive material removal and an incorrect inclination of the grinding wheels can cause a strong grinding pattern on the surfaces and big flaws in the transition areas. Thereby the grinding pattern is created during the first grinding steps and cannot be subsequently compensated by the further polishing steps. The polishing of the surrounding surface only makes the grooves or single scratches particularly visible. Based on currently available results, a strongly visible grinding pattern is only an optical imperfection; a strength reduction could not be observed.

The further correlation of the microscopic records with the bending tensile stresses revealed that flaws in the transition area, like chippings and conchoidals, single scratches and untypical defects are mostly fracturecausing. A repeating occurrence of visible scratches in the direction of the grinding pattern can display a bad condition of a cup wheel. Chipping and conchoidals are a caused by the material removal as a result of the break out at the transition. Different polishing cup wheels can influence the amount and size of the defects.

\subsection{Untypical defects}

Detected untypical defects were correlated with low bending tensile stresses. Therefore, the untypical defects are especially seen as defects that can reduce the edge strength. Since the untypical defects do not run in the grinding direction, it can be assumed that they are generated at the glass edge after the finishing process. Though, glass panes are stored on setting blocks out of silicone which should protect the edges, defects with a direction perpendicular to the edge were detected. Those are critical, as a crack opening through bending tensile stresses is supported. To exclude defects after the finishing process the edge should be protected directly. A possible protection is a direct packaging or a masking the edge with some adhesive tape.

\subsection{Influence of the polishing cup wheels on the transition area}

The variation of chamfer polishing cup wheels has a microscopically detectable influence on the formation of the defects and the edge shape. The synthetic resinbonded polishing cup wheel of the test series A with a fine grain of high-grade corundum ensures sharp-edged transitions. The fine grain does not manage to repair the grooves and flaws in the transition area, which are created during the material removal with diamond grinding cup wheels for the chamfer. Test series B shows a change in the edge geometry due to the soft polishing cup wheel with a medium grain size of high-grade corundum. The combination of the medium grain size with the soft binder results in a round smoothing of the transition area towards the edge surface. The soft bonding system of the polishing cup wheel adapts to the shape of the glass edge and minimally removes the material at the glass edge. The intention of this polishing cup wheel was to specifically improve the edge quality without causing chippings and conchoidals by the material removal and further cause a favourable stress distribution. In spite of the round smoothing, 
flaws in constant size ranges could be detected, which were possibly caused by an additional abrasion.

The polishing cup wheel of test series $\mathrm{C}$ shows the most promising results for the reduction of flaws and higher bending tensile stresses. The polishing cup wheel with a fine-porous composition based on polyurethane and an internal grain size produced a surface image without grooves on the surface and with sharp-edged transitions. The transition area of one side was showing chipping and conchoidals. As a result, the polishing cup wheel is hard enough to repair the surface condition after the processing steps of the diamonds grinding wheels of the chamfer, without creating new flaws.

\subsection{Correlation between the tensile stresses and the fracture-causing defect}

The performed bending tensile stresses showed big scattering. A correlation of the fracture-causing defects revealed reasons for an early breakage and a low bending tensile stresses of single specimen. Furthermore, high bending tensile stresses could not be correlated with clear defects. The fractures origins were found in the edge surface, the chamfer surface, the transition areas and the pane surface. Specimens with a fracture origin from the pane surface and a fracture origin outside the loaded area were not considered in the evaluation. Within the evaluated specimen $60 \%$ of the specimens had a breakage form the chamfer or the transition and $40 \%$ of the edge. A reduction of the flaws in the chamfer and transition areas with special polishing cup wheels can therefore cause higher bending tensile stresses. A higher number of evaluated specimens has to be performed to confirm the results.

\subsection{Edge strength}

The second test series C_2 and KS_2 were performed to determine strength values with a statistical significance. Both resulted in high strength values above the limit value of $36 \mathrm{~N} / \mathrm{mm}^{2}$ according to DIN 18001 (2019). Test series C_2 showed a strength value of $42.74 \mathrm{~N} / \mathrm{mm}^{2}$, test series KS_2 a strength value of $52.09 \mathrm{~N} / \mathrm{mm}^{2}$. The correlation of the fracture-causing defects revealed some untypical defects, which might be the reason for the high amount of fracture origins outside the loaded area. Therefore an even higher edge strength might be producible after improving the conditions of the edges by prevent untypical defects.

\subsection{Use of the microscopic method}

The examinations showed that microscopic method provides meaningful information about the quality of processed glass surfaces. It enables a characterisation of occurring flaws and defects and is further useful for the evaluation of the breaking tests, as fracture-causing defects can be detected. A detailed recording of a rather big surface of $200 \mathrm{~mm}$ of each specimen needs individual adjustments of the microscope, a good computing capacity and some time. It is imaginable that a microscopic method can be used as a support for the adjustment of the grinding machine and a frequent quality check of the edge surface qualities. Hence, the method is useful, but yet not easily adaptable in a practical production chain and needs to be developed further for a possible use in practice.

\section{Summary and outlook}

Defects and flaws naturally occur with processed edges and can not be prevented completely. Nevertheless, the aim of this study was to create polished edges and chamfer surfaces with reduced surface defects and flaws in the transition areas of glass edges. With a specially developed polishing cup wheel of the test series $\mathrm{C}$, a processed chamfer with reduced flaws in the transition areas was produced. Along with that, increasing bending tensile stresses were determined, what further led to the determination of a higher glass edge strength. That shows that the resulting edge quality is influenced strongly by the choice of the polishing cup wheel.

The correlation of the bending tensile stresses and the fracture-causing defects shows that microscopically noticeable defects have an influence on the bending tensile stresses. However, further examinations on the characterisation and geometric measuring of defects need to be performed to specify the influence and boundary values. The correlation as well revealed untypical defects, which led to low bending tensile stresses. Those can weaken the glass noticeable. Therefore, a strong focus in the production chain should be the prevention of untypical defects. 
To generate universal statements and identify relevant parameters, the use of optical methods is beneficial, as the analysis can help to control the production of edge qualities, adjust grinding machines or to detect maladjustments. The method and its reasonable use have to be further developed for a practical use. In the further course of examination, additional process parameters need to be generated. The examinations will first concentrate on one manufacturer before the transferability to a second one. With the generation of further standardised parameters for the finishing processes of glass edges, reproducible glass edges of regulated quality and a generally valid edge strength will be introduced. That will enable a safe and efficient use of annealed glass edges for the design.

Acknowledgements Open Access funding provided by Projekt DEAL. The research project Development of a new grinding process for the chamfer of glass (SAUM - Entwicklung eines neuartigen Schleifprozesses für Bauteile aus Glas) is a joint research project of the Glaswerkstätten Frank Ahne GmbH, Artifex Dr. Lohmann GmbH \& Co. KG and the Institute for Building Construction at the Technische Universität Dresden. It was funded by the Federal Ministry for Economic Affairs and Energy (ZF4123712TA7), as part of the Central Innovation Programme ZIM. Special thanks go to the project partner Glaswerkstätten Frank Ahne GmbH for the good cooperation, technical support and the production of test specimens.

\section{Compliance with ethical standards}

Conflict of interest The authors declare that they have no conflict of interest.

Open Access This article is licensed under a Creative Commons Attribution 4.0 International License, which permits use, sharing, adaptation, distribution and reproduction in any medium or format, as long as you give appropriate credit to the original author(s) and the source, provide a link to the Creative Commons licence, and indicate if changes were made. The images or other third party material in this article are included in the article's Creative Commons licence, unless indicated otherwise in a credit line to the material. If material is not included in the article's Creative Commons licence and your intended use is not permitted by statutory regulation or exceeds the permitted use, you will need to obtain permission directly from the copyright holder. To view a copy of this licence, visit http://creativecommons.org/licenses/ by $/ 4.0 /$.

\section{References}

DIN 1249-11: 2017-05 Glass in building - Part 11: Glass edgesTerms and definitions, characteristics of edge types and finishes. Beuth, Berlin (2017)
DIN EN 1288-3: 2000-09 Glass in building-Determination of the bending strength of glass - Part 3: Test with specimen supported at two points (four point bending), German version EN 1288-3:2000. Beuth, Berlin (2000)

DIN 18008-1: 2019-06 (2019) Glass in Building-Design and construction rules - Part 1: Terms and general bases. Beuth, Berlin (2019)

DIN ISO 6106: Abrasive products-Checking the grain size of superabrasives. Beuth, Berlin (2015)

DIN ISO 8486: Bonded abrasives-Determination and designation of grain size distribution - Part 1: Macrogrits F4 to F220. Beuth, Berlin (1997)

Ensslen, F.: Zwischenbericht aus dem Arbeitskreis Kantenfestigkeit im Fachverband Konstruktiver Glasbau e.V. (FKG). In: Glasbau 2013, Ernst \& Sohn, Berlin (2013). https://doi. org/10.1002/9783433602928.ch9

Ensslen, F., Müller-Braun S.: Kantenfestigkeit von Floatglas in Abhängigkeit von wesentlichen Schneidprozessparametern. In: Glasbau 2017, Ernst \& Sohn, Berlin (2017). https:// doi.org/10.1002/cepa.20

Feldmann, M., Kasper, R. et al.: Guidance for European Structural Design of Glass Components, support of the implementation, harmonization and further development of the Eurocodes. Joint Research Centre (JRC) Scientific and policy Reports of the European Commission, Italy (2014). https://doi.org/10.2788/5523

Kleuderlein, J., Ensslen, F., Schneider, J.: Investigation of edge strength dependent on different types of edge processing. In: Engineered Transparency (2014)

Lindqvist, M.: Structural Glass Strength Prediction Based on Edge Flaw Characterization, Dissertation. École Polytechnique Fédérale de Lausanne. (2013). https://doi.org/10. 5075/epfl-thesis-5627

Lohr, K: Thermisch vorgespanntes Glas mit nachgeschliffenen Kanten. Dissertation. Technische Universität Dresden, Dresden (2019)

Müller-Braun, S., Seel, M., König, M. et al.: Cut edge of annealed float glass: crack system and possibilities to increase the edge strength by adjusting the cutting process. In: Glass Structures \&Engineering 5, pp. 3-25. Springer Nature Switzerland AG, Cham (2020). https://doi.org/10. 1007/s40940-019-00108-3

ÖNORM B 3761-1: Glas im Bauwesen - Konstruktiver GlasbauTeil 1: Grundlagen. Austrian Standards InternationalStandardisierung und Innovation, Wien (2016)

Quinn, G. D.: (2016): Fractography of Ceramics and Glasses. National Institute of Standards and Technology (NIST) Recommended Practise Guide. Special Publication 9616e2, Gaithersburg (2016). https://doi.org/10.6028/NIST. SP.960-16e2

Vandebroek, M. : Thermal Fracture of Glass, Dissertation, Universiteit Gent und Universiteit Antwerpen (2014). https:// hdl.handle.net/10067/1197500151162165141. Accessed: 10 January 2020

Publisher's Note Springer Nature remains neutral with regard to jurisdictional claims in published maps and institutional affiliations. 